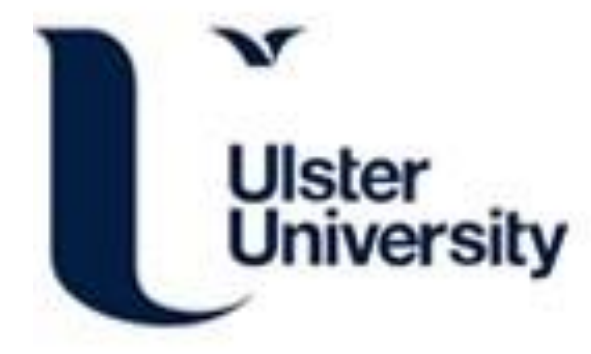

\title{
Ambient Communication Experience (ACE)
}

Hegerty, R., Lunney, T., Curran, K., \& Mulvenna, M. (2009). Ambient Communication Experience (ACE). International Journal of Ambient Computing and Intelligence, 1(2), 53-58. http://www.igiglobal.com/journals/details.asp?id=7825

Link to publication record in Ulster University Research Portal

\section{Published in:}

International Journal of Ambient Computing and Intelligence

Publication Status:

Published (in print/issue): 01/06/2009

\section{Document Version}

Publisher's PDF, also known as Version of record

\section{General rights}

Copyright for the publications made accessible via Ulster University's Research Portal is retained by the author(s) and / or other copyright owners and it is a condition of accessing these publications that users recognise and abide by the legal requirements associated with these rights.

\section{Take down policy}

The Research Portal is Ulster University's institutional repository that provides access to Ulster's research outputs. Every effort has been made to ensure that content in the Research Portal does not infringe any person's rights, or applicable UK laws. If you discover content in the Research Portal that you believe breaches copyright or violates any law, please contact pure-support@ulster.ac.uk. 


\title{
Ambient Communication Experience (ACE) \\ Rosaleen Hegarty, Tom Lunney, Kevin Curran, Maurice Mulvenna \\ University of Ulster, Northern Ireland
}

\begin{abstract}
Ambient Information Systems (AIS), permit a mode of expression that can easily exist at the level of subconscious realisation. Principles of cognition are usually aggregated under the main auditory, visual and often innovative tactile sensory impetus. AIS are designed principally for the aesthetic communication of non-critical information. This research focuses on the development of an Ambient Communication Experience (ACE) system. ACE is a synchronisation framework to provide co-ordinated connectivity across various environmentally distributed devices via sensor data mapping. The intention is to facilitate location-independent and application-responsive screening for the user, leading to the concept of technologically integrated spaces. Technologically integrated spaces have the potential to change our perception of information and our behavioural interactions associated with its provision. The aim is to deliver contextual information without the need for direct user manipulation, and engagement at the level of peripheral perception.
\end{abstract}

\section{Introduction}

Mankoff and Anind (2003) define the development of ubiquity as relying on the concept of user periphery; as any individual's full attention can only be factored to a few applications at any given time. They characterise the success of ambient displays, or ambient information systems as having the capacity to modify the awareness of the user. In turn these systems have the potential to adapt the behaviour of individuals based on the embodied information of the display. Often ambient information bears relevance to only a few individuals, at any given time; therefore the consideration of aesthetics is elementary to such designs, especially when incorporated in work spaces. Ferscha, Emsenhuber, Schmitzberger and Thon (2006) place critical importance on the values of 'purpose', 'contextual relevance' and 'perceivable cohesion' in the conceptual structuring of awareness information. Ambient systems should remain secondary to the primary work task, yet still be easily comprehendible. Within the context of moving information from the periphery to the centre, another important factor is that of user cognitive state (Mankoff \& Anind, 2003). Cognitive state is reflective of the users' in situ and the systems ability to augment their consciousness through sensory 
perception and cognitive behavioural interactions. System activity is operating on users' multimodal senses below the threshold of consciousness, requiring only subconscious recognition (Baars \& Mc Govern, 1996). Screen based media and associated physical architectural space provide the medium for investigative studies in this area. The behavioural characteristics (as defined by Pousman \& Stasko, 2006) of ambient information systems include the following:

- The presentation is of non-critical information.

- Information that can move from the periphery to the centre of the user's focus.

- The concentration is on 'the tangible' in the form of real objects in the environment.

- AIS provide non-distracting subtle changes reflecting information updates.

- AIS should in essence be aesthetically pleasing and environmentally suitable (Pousman \& Stasko, 2006).

They further elaborate on the design space of AIS by defining the dimensions that create it: (i) reflecting on the information capacity of the system; (ii) the possible notification level of the design; (iii) representational fidelity from within the product; (iv) the aesthetic emphasis of the presentation (based on the work of Ferscha et al., 2006). Finally they propose an evaluation framework based on these dimensions (see Pousman \& Stasko, 2006).

\section{Motivation}

The main motivation for this research is to provide sensor-activated communication. This will enable contextualised content viewing. Mobile devices offer convenient communication capabilities and have the potential to create intermediary support for the user and their environment enhancing an intelligent space. The ACE system's function is in the autonomous realisation of a user's presence through Radio Frequency IDentification-RFID readings with the expected objective of delivering contextual personal preferences permitting implicit interaction within the system. This communication will permit a many to many (n:n) exchange via shared distributed devices utilised in smart architectural space enabling the creation of surround and fluid protean displays. The 'ambientROOM' project is an example of such but incorporating a broad range of various interactions from light patches, soundscapes and water ripples. The aim of 'ambientROOM' is to extend and augment Human Computer Interaction beyond computer screens (Wisneski, Ishii, Dahley, Gorbet, Brave, 
Ullmer \& Yarin, 1998). Carbonell (2006) reflects on ambient interface interactions as having to be reconfigured for throughput to output terminals of varying media and screen dimensions. This concept is reflected in the ACE system components of PC, PDA, flat screen and smart mobile phone, and possibly further mobile devices and stationary artefacts. A one to many (1:n) configuration is substantiated when a user's tag reading activates a within range device display. Implementation of these constraints gives rise to 'interface plasticity' and 'adaptive multimodality' (Calvary, Thevenin, \& Coutaz, 2003). However maintaining simplicity whilst asserting notions of 'calm' remains the consummation in these phenomena and a reflection of the technology we seek (Weiser, 1991).

The classic AIS example is Jeremijenko's Display Installation entitled 'Live Wire', which attracts either aural or visual attention as the incitement requires. More recent ambient displays include 'The Kandinsky system', which generates aesthetic information collages converting textual input to image output (Fogarty, Forlizzi \& Hudson, 2001). 'IMPACT' monitors daily physical activity and provides feedback through detailed and abstracted displays (Forlizzi, Li, \& Dey, 2007). ‘Ambient Orb’ presents ambient information through wireless configurations to track personal portfolio interests such as market shares. 'Hello.wall' uses a large ambient display coupled with a hand-held device exploiting the ability to perceive information via codes (Vogel \& Balakrishnan, 2004). Consistently the purpose is to refine knowledge to a symbolic representation requiring little cognitive effort. An ethical issue that arises is that the abstracted notation of information is reliable and consistent for the initiated users specified; otherwise it could lose all purposeful functionality. Privacy related data for example may need to be tagged as 'sensitive' and filtered away from any public audience.

\section{ACE Architecture}

The key components of ACE (Figure 1) collaborate to ensure continuity of the user experience and include a sensor network, web server, session server, and user session client (to store user history, cookies, current web page state and bookmarks amongst other user facilities) to different displays. 


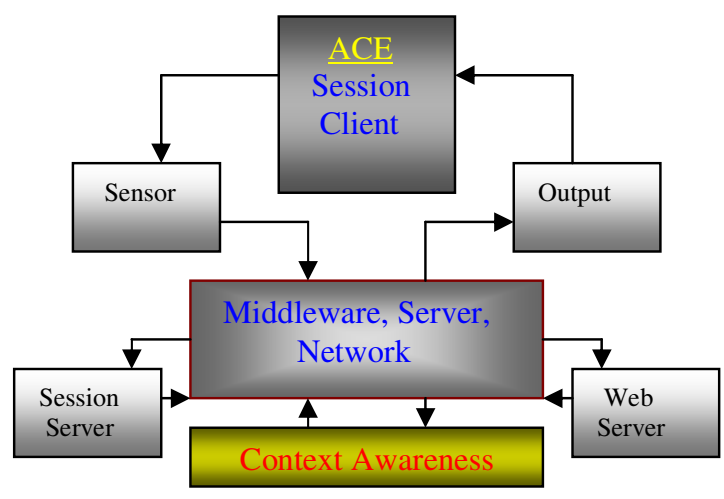

Figure 1: High-level schematic of ACE

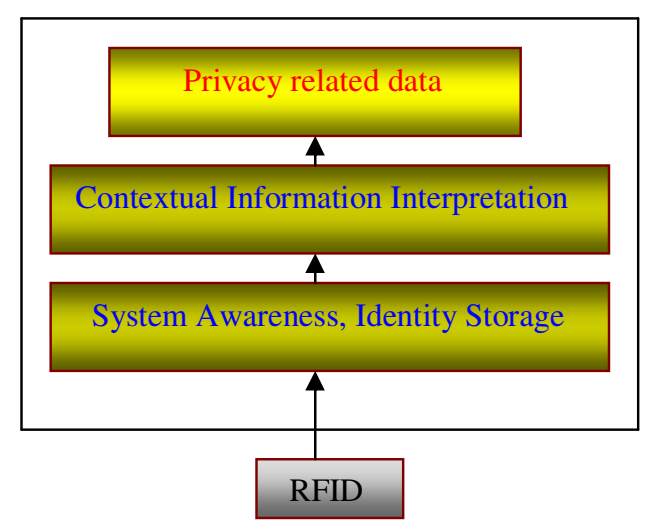

Figure 2: Context aware components

The server side can act as a coordinator to manage the data, and facilitate screen resizing before exporting content to a newly activated device. The client side component will have the necessary functionality to manage session synchronisation. The server must also maintain a user's personal profile and orchestrate this profile to heterogeneous devices within dynamic environments. In addition the server will also be responsible for carrying out routine authentication and authorisation and provide session state and mobility handling within the system. The components associated with context awareness (Figure 2) facilitate user recognition, identification and storage within the first layer, with interpretation of this information addressed at level 2. Privacy related data may need to be tagged at level 3 as 'sensitive' to enable security filtering of data for display purposes.

Amongst the challenges for this system, there exists the requirement to work in real-time and to cope with varying levels of ambiguity, such as changes in user predilection, user idiosyncratic actions and weak sensor signals. Adaptability to new heterogeneous devices and amended environments will result in readjustment to meet user specification and compensate for device failure supporting integration and interoperability. Whilst dynamically adapting to user requirements through reconfiguration, 'trust,' 'security' and 'safety' standards must also be adhered to, and integrated into the system design. The core of the application architecture is to provide natural interactions and hence requires abstraction of the underlying technical communication infrastructure; hiding complexity, whilst enhancing experience and confidence. Successful ubiquity however, requires appropriate transparency integrated into the ecology of ones environment facilitated through peripheral interfacing. 
The ability to capture the context of the user in state, application and service requires interpretation of 'W6'; the 'Who?,' 'What?,' 'Why?,' 'Where?,' 'When?' and 'hoW?' and is central to the design and profile of the user. Context is argued to be a feature of interaction in any human-computer symbiosis (Dourish, 2004). It is based on the premise that intelligence is action orientated and context can be used to bring order and clarity to unclear situations in order to deliver appropriate actions. Therefore context is seen as a tool for action selection. Within ACE providing device interchange while sustaining the capabilities and resources of the current screening is part enabled by context awareness. Location information is another form of context aware information within ACE. A migration theory associated with user perception may also be incorporated further into the design of ACE as a means to capture key information concerning the user. This modelling may need to encapsulate the user's intentions towards a particular display terminal, taking into account the capabilities of the display equipment and the surrounding interface options. This will provide additional information for the user, concerning the information content and available screen display real estate.

\section{Conclusion}

As technology advances, art begins to resemble science; the interpretation of data through artistic creations reflects a form of compression. "Content and presentation become everything; form and function must be fused" (Walker, 2003). It has been noted amongst the theorists of Cognitive Science that much of cognition concerns compression (Wolff, 1982). AIS systems are reflective of cognitive systems in that they unite cognitive economy and principles of information compression, where the main goal is in the concentration and computation of data and the encoding to a form that is later retrieved and comprehended (Chater, 2002; Wolff, 2006). Many aspects of cognition, from perception, language acquisition, to high-level cognition involve finding patterns that provide the simplest explanation of available data enabling categorisation and causal relations. The emphasis is on simplicity, and ease of use. Denning and Metcalfe (1998) affirm, "to become attuned to more information is to attend to it less," this is where the design of AIS resides, and is the context of this research. 


\section{References}

Baars, B. J., Mc Govern, K. (1996). Cognitive views of consciousness, What are the facts? How can we explain them?" In The Science of Consciousness (eds.)M. Veldmans Routledge Press, 69.

Calvary, G., Thevenin, D., Coutaz, J. (2003). A Reference Framework for the Development of Plastic User Interfaces. Retrieved May 20, 2008, from http://iihm.imag.fr/publs/2003/MuiBook03.pdf

Carbonell, N. (2006). Ambient Multimodality: towards Advancing Computer Accessibility and Assisted Living. International Journal on Universal Access in the Information Society, 18-26.

Chater, N. (2002). Simplicity: A unifying principle in cognitive science. Retrieved November 16, 2008, from http://homepages.cwi.n/ paulv/papers/tcs02.pdf

Denning, P. J., Metcalfe, R. M. (1998). Beyond Calculation: The Next Fifty Years of Computing, Springer, 83-84.

Dourish, P. (2004). What we talk about when we talk about context. Personal and Ubiquitous Computing 8(1), 19-33.

Ferscha, A., Emsenhuber, B., Schmitzberger, H., Thon P. (2006). Aesthetic Awareness Displays. In T. Pfeifer et al. (eds.): Advances in Pervasive Computing 2006 Adjunct Proceedings of Pervasive 2006, books@OCG.at Vol. 207, ISBN 3-85403-207-2.

Fogarty, J., Forlizzi, J., Hudson, S.E. (2001). Aesthetic Information Collages: Generating Decorative Displays that Contain Information .Proceedings, ACM Press, 141-150.

Forlizzi, J., Li, I., Dey, A. (2007). Ambient Interfaces that Motivate Changes in Human Behaviour. Retrieved May 20, 2008, from http://ftp.informatik.rwth-aachen.de/Publication/CEUR-WS/Vol-254/paper02.pdf

Mankoff, J., Dey, A.K. (2003). From conception to design: a practical guide to designing ambient displays. In K. Ohara \& E. Churchill (eds.), Public and Situated Displays. Kluwer. Retrieved November 15, 2008, from http://www.intelresearch.net/Publications/Berkeley/072920031038_155.pdf

Pousman, Z., Stasko, J. (2006). A taxonomy of ambient information systems: four patterns of design. Proceedings of the working conference on advanced visual interfaces, 67-74. Retrieved November 13, 2008, from http://www.cc.gatech.edu/ john.stasko/papers/avi06.pdf 
Vogel, D., Balakrishnan, R. (2004). Interactive Public Ambient Displays: Transitioning from Implicit to Explicit, Public to Personal, Interaction with Multiple Users. Retrieved May 20, 2008, from http://www.dgp.toronto.edu/ ravin/papers/uist2004_ambient.pdf

Walker, K. (2003). Interactive and Informative Art. In D. Duncan Seligman (eds.), Artful Media. IEEE Xplore. Retrieved November 12, 2008, from http://ieeexplore.iee.org/stamp/stamp.jsp?arnumber=1167916\&isnumber=26330

Weiser, M. (1991). The Computer for the Twenty-First Century, in Scientific American, 94104.

Wisneski, G., Ishii, H., Dahley, A., Gorbet, M., Brave, S., Ullmer, B., Yarin, P. (1998).

Ambient display: turning architectural space into an interface between people and digital Information. In N.A. Streitz, S. Konomi \& H-J. Burkhardt (eds), Cooperative buildings. Proceedings of the First International Workshop on Cooperative Buildings. Lecture Notes in Computer Science 1370; Springer-Verlag, Heidelberg; 22-32.

Wolff, J.G. (1982). Language acquisition, data compression and generalization. In Language and Communication 2, 57-89.

Wolff, J.G. (2006). Information Compression by Multiple Alignment, Unification and Search as a Unifying Principle in Computing and Cognition. Retrieved 16 November 2008, from http://www.citebase.org/fulltext?format=application/pdf\&identifier=oai:arXiv.org:cs/030705 


\section{Biographical Sketches of Authors}

Rosaleen Hegarty BSc (Hons) is a PhD student researching in the area of Ambient Intelligence in the School of Computing and Intelligent Systems, Faculty of Computing and Engineering at the University of Ulster, Magee College.

Dr. Tom Lunney BSc (Hons), MSc, P.G.C.E, PhD, MIEEE, MBCS received his degrees from Queen's University Belfast, and is now a Senior Lecturer in Computer Science in the University of Ulster. His research areas include concurrent and distributed systems, artificial intelligence and multi-modal computing. He has presented papers at a range of International Conferences and participated in the organising committees for a number of international conferences and workshops. He has taught at other educational institutions including Queens University, Belfast and The University of Pau, France. He is currently Course Director for postgraduate masters programmes in the University of Ulster.

Kevin Curran BSc (Hons), PhD, SMIEEE, MBCS CITP, MACM, MIEE, FHEA has made significant contributions to advancing the knowledge and understanding of computer networking, evidenced by over 350 publications. He is a regular contributor to $\mathrm{BBC}$ radio \& TV news in Northern Ireland and is listed in the Dictionary of International Biography, Marquis Who's Who in Science and Engineering and by Who's Who in the World. He has chaired sessions and participated in the organising committees for many highly-respected international conferences and workshops. He is the Editor in Chief of the International Journal of Ambient Computing and Intelligence and has served as an advisor to the British Computer Society in regard to computer industry standards.

Dr. Maurice Mulvenna received his degrees from the University of Ulster, where he is a senior lecturer in computer science. He researches artificial intelligence and pervasive computing and serves on many program committees, including IEEE Pervasive Computing, IEEE Pervasive Computing and Applications, Pervasive Systems and Computing and IEEEACM Web Intelligence. He is a senior member of both the IEEE and Association for Computing Machinery (ACM), and is a chartered member of the British Computer Society (BCS). 